\title{
Substituição do leite de cabra por soro de queijo bovino para cabritos alpinos
}

\author{
Roberto Germano Costa ${ }^{1}$, Edvaldo Mesquita Beltrão Filho ${ }^{1}$, Geovergue Rodrigues de \\ Medeiros $^{2}$, Arturo Bernardo Selaive Villarroel ${ }^{3}$, Sandra Elisabeth Santiago Beltrão Santa \\ Cruz $^{1}$, Edson Mauro Santos ${ }^{2}$
}

\footnotetext{
1 UFPB - Campus Bananeiras.

2 Instituto Nacional do Semi-Árido - INSA

${ }^{3}$ Departamento de Zootecnia - UFC.
}

RESUMO - O trabalho foi conduzido para avaliar a substituição do leite de cabra por soro de queijo bovino no aleitamento de cabritos alpinos. Os animais foram distribuídos em delineamento inteiramente casualizado, em arranjo fatorial $4 \times 2$, composto de quatro níveis de substituição do leite de cabra por soro de queijo ( $0,15,30$ e 45\%) e dois sexos (três machos e quatro fêmeas por tratamento). A inclusão do soro de queijo na dieta não afetou o desenvolvimento ponderal dos cabritos dos 7 aos 42 dias de idade. Os cabritos alimentados com leite de cabra apresentaram maiores pesos finais, em torno de 13,0 kg; consumiram 70,0 litros/animal de leite de cabra, 172,0 g MS/animal/dia de concentrado e tiveram ganho médio de 137,5 g/dia. Nos cabritos alimentados com a dieta com 15, 30 e 45\% de soro de queijo, os pesos finais foram de 11,1; 9,88 e 10,27 kg; o consumo de leite foi de 59,5; 49,0 e 38,4 litros/animal; e o de concentrado, 148,0; 117,0 e $135 \mathrm{~g} \mathrm{MS} / \mathrm{animal} / \mathrm{dia}$, com ganhos de 122,2; 99,5 e 100,8 g/dia, respectivamente. A conversão alimentar não diferiu entre as dietas. O efeito do sexo evidenciou-se a partir dos 21 dias de idade, mas não houve interação dieta $\times$ sexo. Ao final do estudo, aos 70 dias de idade, o peso dos machos $(12,4 \mathrm{~kg})$ foi maior que o das fêmeas $(10,6 \mathrm{~kg})$. A maior rentabilidade média $(168,15 \%)$ foi obtida com o fornecimento dos níveis mais altos de soro de leite. O aleitamento de cabritos com até $45 \%$ de soro de queijo é tecnicamente viável e proporciona melhor retorno econômico. O uso de leite integral de cabra para criação de cabritos em rebanhos leiteiros é economicamente inviável.

Palavras-chave: aleitamento artificial, avaliação econômica, crescimento, sucedâneos do leite

\section{Replacement of goat milk for cattle cheese whey in artificial feeding of Alpine kids}

ABSTRACT - The objective of this work was to evaluate the replacement of whole goat milk for cattle cheese whey in the artificial nursing of alpine kids. The animals were distributed in a complete randomized design in a $4 \times 2$ factorial arrangement made up with four levels of goat milk replacing for cheese whey (0, 15, 30 and 45\%) and two sexes (three males and four females per treatment). The inclusion of cheese whey in the diet did not affect the growth of the kids from 7 to 42 days of age. Kids fed whole goat milk showed higher final weights, around $13.0 \mathrm{~kg}$. They intaked $70.0 \mathrm{~L} /$ animal of whole goat milk, $172.0 \mathrm{~g} \mathrm{DM} /$ animal/day of concentrate and they had an average gain of $137.5 \mathrm{~g} / \mathrm{day}$. For the kids fed with 15, 30, 45\% cheese whey diet, the final weights were 11.1; 9.88 and $10.27 \mathrm{~kg}$; the whole goat milk consumption was 59.5, 49.0 and $38.4 \mathrm{~L} /$ animal, the concentrate consumption was 148.0; 117.0 and $135 \mathrm{~g}$ DM/animal/day with gains of 122.2; 99.5 and $100.8 \mathrm{~g} /$ day, respectively. Food conversion did not differ among diets. The sex effect was evident from the age of 21 days but there was not a treatment $\times$ sex interaction. At the end of the work, at 70 days of age, the weight of the males $(12.4 \mathrm{~kg})$ was higher than the female weights $(10.6 \mathrm{~kg})$. The highest average yield $(168.15 \%)$ was obtained when the kids received maximum level of whey. Nursing kids with up to $45 \%$ of cattle cheese whey is technically viable and increases economic return. However, using whole milk goat for nursing kids in milk cattle is economically unviable.

Key Words: artificial nursing, economic evaluations, growth, milk replacer

Recebido em 20/2/2008 e aprovado em 24/4/2009.

Correspondências devem ser enviadas para: betogermano@hotmail.com 


\section{Introdução}

É notória a importância econômica e social da caprinocultura leiteira no Nordeste brasileiro, a qual detém cerca de $91,36 \%$ do efetivo nacional (IBGE, 2008). Para essa região, onde as condições edafo-climáticas dificultam a exploração agrícola, a caprinocultura já consolidou sua importância e viabilidade, despertando o interesse de criadores em explorar o leite ou a carne e pele, como na microrregião do Cariri Oriental, estado da Paraíba, que produz diariamente cerca de 18 mil litros de leite de cabra.

É prática usual nas unidades produtoras de leite a separação dos cabritos das mães logo após a fase de ingestão do colostro, quando passam a ser aleitados artificialmente ou são descartados, principalmente os machos, logo após o nascimento, visando elevar a disponibilidade de leite de cabra para a comercialização. Outra opção é o cruzamento das cabras leiteiras com raças paternas específicas para corte visando obter animais com melhor desenvolvimento da carcaça, de forma a comercializar os cabritos a preços mais elevados. Esse direcionamento reprodutivo, no entanto, não deve ser aplicado a todas as cabras do rebanho leiteiro, sob risco da perda de genes para produção de leite nas gerações futuras.

Por outro lado, a criação de cabritos de origem leiteira visando à produção de carne pode se transformar numa prática onerosa de acordo com a fonte de leite disponibilizada aos animais durante a fase de aleitamento. Ribeiro et al. (1997) comentaram que as despesas com alimentação dos animais na caprinocultura leiteira representam 50 a $60 \%$ dos custos de produção e podem atingir até $80 \%$.

Nesse contexto, a busca por alternativas que possam reduzir os custos com o fornecimento de alimentos aos cabritos e garantir maior retorno econômico para os produtores são fatores importantes para a sustentabilidade da atividade leiteira (Oliveira et al. 2010). Vários sucedâneos, como o de soro de queijo caprino ou bovino, pelo seu valor nutricional e baixo custo de aquisição, têm sido utilizados para aleitamento de cabritos na fase de cria.

Montenegro et al. (1998) e Beserra et al. (2003) asseguram que o soro de queijo de cabra pode ser utilizado em níveis de 20 a $60 \%$ de substituição ao leite de vaca, pois não prejudica o desenvolvimento dos cabritos e permite reduzir os custos de produção desses animais.

Além disso, a utilização do soro de queijo na alimentação animal tem contribuído para redução dos efluentes líquidos lançados ao meio ambiente pelas indústrias de laticínios (Machado et al., 2001).
Este trabalho foi realizado com o objetivo de avaliar o efeito da substituição do leite de cabra por soro de queijo de leite bovino sobre o desempenho produtivo e econômico de cabritos alpinos machos e fêmeas na fase de cria.

\section{Material e Métodos}

O experimento foi realizado no Setor de Caprinocultura do Centro de Ciências Humanas, Sociais e Agrárias da Universidade Federal da Paraíba, Campus III, Bananeiras, Paraíba, microrregião do Brejo Paraibano. Foram utilizados 28 cabritos alpinos separados das mães logo após o nascimento e com peso médio de 3,01 $\pm 0,75 \mathrm{~kg}$ ao nascer.

O colostro foi administrado inicialmente até as primeiras seis horas de vida em mamadeiras individuais à vontade, prosseguindo o manejo durante três dias consecutivos. Posteriormente, o manejo alimentar adotado consistiu do fornecimento à vontade de feno de capim-tifton (Cynodon sp.) e concentrado comercial na forma peletizada, seguido do fornecimento $1,0 \mathrm{~L} / \mathrm{animal} / \mathrm{dia}$ de leite de cabra e soro de queijo bovino, dividido em duas refeições. As dietas foram: leite de cabra integral; leite de cabra (85\%) e soro de queijo (15\%); leite de cabra (70\%) e soro de queijo (30\%); e leite de cabra (55\%) e soro de queijo (45\%). Os animais foram alojados em galpão coberto, medindo $25 \times 10 \mathrm{~m}$, em baias coletivas, com três machos e quatro fêmeas por dieta. As baias eram de piso ripado, suspenso, providas de comedouro, bebedouro e mamadeira individual.

A dieta sólida foi fornecida à vontade, a partir do $15 \underline{0}$ dia, e quantificada diariamente a partir do $21^{\circ}$ e a até o $70^{\circ}$ dia, permitindo-se sobras correspondentes a $20 \%$ do total fornecido. Os cabritos foram pesados a cada sete dias, com jejum alimentar prévio (concentrado, feno, leite e soro) de 16 horas. Não houve restrição de água durante o período de jejum.

O concentrado comercial era peletizado, composto de farelo de trigo, gérmen de milho, calcário calcítico, melaço, cloreto de sódio, farelo de soja, milho moído, premix vitamínico mineral e probiótico (Tabela 1). O probiótico foi utilizado como promotor de crescimento com o objetivo de aumentar a eficiência alimentar e o ganho de peso dos animais.

O soro de queijo de leite de vaca utilizado foi obtido no Setor de Laticínios do CCHSA/UFPB e congelado a $-18^{\circ} \mathrm{C}$ para conservação, sendo descongelado diariamente para fornecimento aos cabritos. A mistura leite e soro foi realizada nas proporções condizentes aos tratamentos e aquecida a $38^{\circ} \mathrm{C}$ para fornecimento usando-se mamadeiras individuais, com oferta de $500 \mathrm{~mL}$ às $7 \mathrm{~h} 30$ e $500 \mathrm{~mL}$ às $15 \mathrm{~h}$, de modo que não ocorressem sobras da bebida láctea. 
Tabela 1 - Composição bromatológica dos ingredientes (\% da MS)

\begin{tabular}{|c|c|c|c|c|c|c|}
\hline Ingrediente & Matéria seca & Proteína bruta & Extrato etéreo & $\begin{array}{c}\text { Fibra em detergente } \\
\text { neutro }\end{array}$ & Cálcio & Fósforo \\
\hline Feno de capim-tifton & 90,72 & 9,7 & 2,1 & 77,6 & 0,36 & 0,20 \\
\hline Concentrado comercial & 88,0 & 18,0 & 2,5 & - & 1,2 & 0,5 \\
\hline Leite de cabra ${ }^{1,2}$ & 11,67 & 3,66 & 4,05 & - & 0,13 & 0,16 \\
\hline Soro de queijo bovino 1,3 & 6,24 & 1,41 & 0,73 & _ & 0,05 & 0,045 \\
\hline
\end{tabular}

${ }^{1}$ Valadares Filho et al. (2006).

2 Nunes (1998).

${ }^{3}$ Martins et al. (2008).

A análise econômica consistiu da produção do cabrito e do custo com alimentação (leite, soro de queijo, feno e concentrado comercial peletizado). Considerou-se o preço de comercialização do animal, em torno de R\$3,50/kg de peso de vivo (outubro/2007), conforme cotação média do dólar comercial em outubro de 2007, de R\$1,80 (Ministério da Fazenda, 2007).

No cálculo dos custos da ração, considerou-se o valor de mercado do concentrado peletizado para bezerros e de feno de capim-tifton, que foram de R $\$ 0,80 / \mathrm{kg}$ e R \$ 0,85/kg, respectivamente. Os custos de mão-de-obra e de instalações foram considerados fixos.

Para a análise econômica, utilizou-se a metodologia de Lana et al. (1999), com as variáveis calculadas da seguinte forma: Receita bruta média (RBM): considerando o peso do cabrito (PC) versus o preço do kg de peso vivo, definida por: RBM = PC $\times$ Pkg; Custos com alimentação (CAL): obtido pela multiplicação do total de ração consumida (RC) pelo seu preço $(\mathrm{PR})$, definido por: $\mathrm{CAL}=\mathrm{RC} \times \mathrm{PR}$; Margem bruta média (MBM): obtida pela diferença entre a receita bruta e os gastos com alimentação: $\mathrm{MBM}=\mathrm{RBM}-\mathrm{CA}$; Rentabilidade média (RM) considerando a margem bruta média dividida pelo custo de alimentação e multiplicando-se por $100: \mathrm{RM}=(\mathrm{MBM} / \mathrm{CA}) \times 100$.
O delineamento experimental utilizado foi o inteiramente casualizado em arranjo fatorial $4 \times 2$, com quatro níveis de substituição do leite de cabra por soro de queijo bovino e dois sexos, três machos e quatro fêmeas por dieta. Foram realizadas análises de variância e as médias comparadas pelo teste Duncan a $5 \%$ de probabilidade, com auxílio computacional do programa SAS (1997).

\section{Resultados e Discussão}

Entre os 7 e 42 dias de vida, a inclusão do soro de queijo bovino nos níveis de 15 a 45\% não afetou $(\mathrm{P}>0,05)$ o desenvolvimento ponderal dos cabritos. Nesse período os animais apresentaram crescimento normal e não houve mortalidade (Tabela 2).

Nos primeiros sete dias de idade, os cabritos alimentados com dietas contendo 30 e $45 \%$ de soro de queijo apresentaram diarreia, possivelmente em decorrência do alto teor de lactose no soro de queijo, aproximadamente 78,8\% na matéria seca (Valadares Filho et al., 2006). Ocorrência semelhante foi observada por Galina et al. (1995) em cabritos alimentados com $50 \%$ de soro de queijo. Por outro lado, a partir dos 21 dias de idade, além da dieta líquida, os animais receberam gradualmente crescentes

Tabela 2 - Desempenho ponderal de cabritos alimentados com soro de queijo bovino em substituição ao leite de cabra

\begin{tabular}{|c|c|c|c|c|c|c|}
\hline & \multicolumn{4}{|c|}{ Nível de soro de queijo bovino (\%) } & \multicolumn{2}{|c|}{ ANOVA } \\
\hline & 0 & 15 & 30 & 45 & Tratamento & CV (\%) \\
\hline \multicolumn{7}{|l|}{ Peso (kg) } \\
\hline Aos 7 dias & 3,77 & 3,05 & 2,87 & 3,67 & ns & 21,86 \\
\hline Aos 14 dias & 4,38 & 3,72 & 3,85 & 4,54 & ns & 19,95 \\
\hline Aos 21 dias & 5,25 & 4,65 & 4,61 & 4,88 & ns & 20,05 \\
\hline Aos 28 dias & $6,24 a$ & $4,62 b$ & $5,08 \mathrm{ab}$ & $5,72 \mathrm{ab}$ & $*$ & 19,23 \\
\hline Aos 35 dias & 7,00 & 5,92 & 5,98 & 6,50 & ns & 15,50 \\
\hline Aos 42 dias & 7,88 & 6,95 & 7,28 & 7,35 & ns & 15,95 \\
\hline Aos 49 dias & $9,37 \mathrm{a}$ & $7,52 b$ & $7,70 \mathrm{~b}$ & $8,34 \mathrm{ab}$ & $*$ & 12,81 \\
\hline Aos 56 dias & 9,87 & 8,97 & 8,61 & 9,47 & ns & 13,44 \\
\hline Aos 63 dias & $12,15 a$ & $10,20 b$ & $8,85 b$ & $9,95 b$ & $*$ & 13,20 \\
\hline Aos 70 dias & $13,00 \mathrm{a}$ & $11,10 \mathrm{~b}$ & $9,88 b$ & $10,27 b$ & $*$ & 13,23 \\
\hline \multicolumn{7}{|c|}{ Ganho de peso diário (g/dia) } \\
\hline Nascimento aos 70 dias & $137,5 \mathrm{a}$ & $122,2 \mathrm{a}$ & 99,5b & $100,8 b$ & $*$ & 15,64 \\
\hline 28 aos 70 dias & $161,0 \mathrm{a}$ & $154,2 \mathrm{a}$ & $114,2 b$ & $108,3 b$ & $*$ & 19,93 \\
\hline
\end{tabular}

Médias com letras diferentes nas linhas são significativas $(\mathrm{P}<0,05)$ pelo teste Duncan. 
níveis de concentrado e feno, o que contribuiu para elevar o aporte de nutrientes, principalmente energia e proteína, e para estimular o desenvolvimento do rúmen, por meio do crescimento das papilas ruminais, promovido pelos ácidos graxos voláteis da fermentação desses alimentos, e da inoculação da microbiota ruminal, como reportam Lyford Jr. (1993) e Van Soest (1994), além de reduzir o estresse dos cabritos ao desaleitamento, facilitando o desmame precoce.

A partir dos 49 aos 70 dias de vida, os cabritos alimentados com leite de cabra integral apresentaram maiores pesos corporais $(\mathrm{P}<0,05)$ em relação àqueles que receberam soro de queijo, com valores variando de 9,37 a 13,0; 7,52 a 11,$1 ; 7,7$ a 9,88 e 8,34 a 10,27 kg para as dietas com 0, 15, 30 e $45 \%$ de soro de queijo, respectivamente.

Essa superioridade no peso é reflexo do melhor valor nutritivo do leite integral de cabra e do maior consumo de concentrado por esses animais, em torno de 172,0 g MS/dia (Figura 1), o que proporcionou ganhos médios de 137,5 e $161,0 \mathrm{~g} /$ dia do nascimento aos 70 dias e dos 28 aos 70 dias de idade, respectivamente, embora não tenha sido diferente $(\mathrm{P}>0,05)$ da dieta com $15 \%$ de soro. Os cabritos desse grupo consumiram em torno de 70 litros de leite de cabra/animal durante o período experimental, já que o fornecimento foi de 1,0 L/animal/dia.

Valores próximos aos observados neste trabalho foram reportados por Genandoy et al. (2002), que observaram ganho de peso de 151,0 g/dia em cabritos da raça Alpina alimentados à vontade com leite de vaca como alimento exclusivo e ganho de 149,0 g/dia em animais recebendo $1,0 \mathrm{~kg}$ leite/dia mais concentrado, durante 70 dias.

Entre os animais alimentados com soro de queijo, o maior crescimento foi obtido com a dieta com 15\%, com ganho médio de 154,2 g/dia, estatisticamente semelhante ao valor encontrado com oferta de dieta líquida com leite de cabra

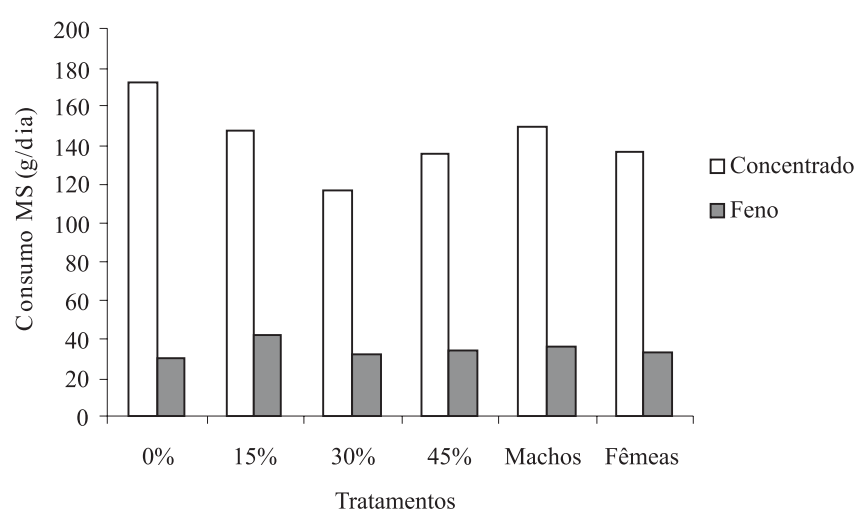

Figura 1 - Consumo de concentrado e feno em cabritos dos 21 aos 70 dias de idade alimentados com soro de queijo bovino em substituição ao leite de cabra. integral (161,0 g/dia), e superior aos 114,2 e 108,3 g/dia obtido com os demais níveis de soro no aleitamento, os quais podem ser considerados satisfatórios e evidenciam o potencial desse sucedâneo na alimentação de cabritos, refletindo na redução de custos de alimentação e maior disponibilidade de leite de cabra para comercialização. Para substituição eficiente do leite de cabra por sucedâneos, deve-se considerar a fonte do sucedâneo, o valor nutritivo e, especialmente, a concentração de energia associada à qualidade da proteína, fundamentais para o crescimento de cabritos (Galina et al., 1995).

Nas dietas com 15; 30 e 45\% de substituição do leite por soro, os valores médios no consumo de leite de cabra foram de 59,5; 49,0 e 38,5 L/animal; de soro de queijo 10,5; 21,0 e 31,5 L/animal, considerando o fornecimento fixo de $1,0 \mathrm{~L}$ da dieta líquida/animal/dia durante 70 dias. O consumo de concentrado foi de aproximadamente 148,0; 117,0 e 135,0 g/ animal/dia (Figura 1), respectivamente, para as três dietas. Apesar do menor ganho de peso, a redução no consumo de leite e de concentrado pode justificar a utilização do soro de queijo, em razão da diminuição dos custos de criação dos cabritos.

Montenegro et al. (1998) reportaram que a substituição do leite de vaca por soro de queijo de cabra nos níveis de 0 a $60 \%$ não diminuiu o ganho de peso diário, o peso final e o rendimento de carcaça de cabritos mestiços, o que permitiu desenvolvimento satisfatório dos 35 aos 84 dias de idade. Também utilizando soro de queijo de cabra no aleitamento de cabritos, Beserra et al. (2003) relatam que aos 72 dias os pesos finais dos cabritos variaram de 10,0 a $13,4 \mathrm{~kg}$. Assim, pela disponibilidade e baixo valor comercial do soro de queijo bovino in natura nas usinas de beneficiamento de leite e nas unidades rurais produtoras de queijo, o soro pode ser uma alternativa como sucedâneo na dieta láctea dos cabritos.

Os animais que receberam soro de queijo consumiram em torno de 41,8; 32,0 e 34,3 g MS de feno/dia, valores superiores aos determinados em cabritos alimentados com leite de cabra integral (29,4 g MS de feno/dia), confirmando o efeito significativo $(\mathrm{P}<0,05)$ dos percentuais de substituição do leite de cabra por soro de queijo bovino no consumo de feno. Isso sugere que o consumo de alimento sólido nas primeiras semanas de vida é o fator mais importante na transição de pré-ruminante para ruminante adulto, e que as estruturas do pré-estomago têm capacidade adaptativa em razão da dieta.

Houve efeito significativo $(\mathrm{P}<0,05)$ do nível de substituição do leite de cabra pelo soro de queijo bovino sobre o consumo médio de matéria seca da dieta total (leite/soro, concentrado e feno) e proteína bruta (Tabela 3). 
Tabela 3 - Consumo de matéria seca, proteína bruta e conversão alimentar de cabritos alimentados com soro de queijo bovino em substituição ao leite de cabra na dieta

\begin{tabular}{|c|c|c|c|c|c|}
\hline \multirow[t]{2}{*}{ Variável } & \multicolumn{4}{|c|}{ Nível de substituição (\%) } & \multirow{2}{*}{$\begin{array}{l}\text { CV } \\
(\%)\end{array}$} \\
\hline & 0 & 15 & 30 & 45 & \\
\hline Consumo médio de matéria seca (g /dia) & $318,1 \mathrm{a}$ & $313,7 \mathrm{a}$ & $263,3 a b$ & $250,3 b$ & 16,57 \\
\hline Consumo médio de proteína bruta (g/dia) & $70,3 a$ & $64,5 a$ & $52,3 b$ & $51,6 b$ & 12,83 \\
\hline Conversão alimentar (g MS dia/g GPD) ${ }^{1}$ & 2,38 & 2,53 & 2,65 & 2,48 & 27,97 \\
\hline Eficiência alimentar (\%) & 43,22 & 38,95 & 37,78 & 40,27 & 22,74 \\
\hline
\end{tabular}

${ }^{1}$ Média de consumo diário de matéria seca do nascimento aos 70 dias/ganho de peso diário do nascimento aos 70 dias de idade.

Médias com letras diferentes nas linhas são significativas $(\mathrm{P}<0,05)$ pelo teste Duncan.

Os cabritos alimentados com leite de cabra integral e com $15 \%$ de soro de queijo consumiram maiores quantidades de matéria seca da dieta total, com valores de 318,1 e 313,7 g/MS/dia, enquanto aqueles mantidos com a dieta líquida com 30 e $45 \%$ de soro de queijo consumiram em torno de 263,3 e 250,3 g/MS/dia, respectivamente. Esse fato pode ser explicado pelos maiores consumos de leite de cabra, cujo teor de MS é superior ao de soro de queijo (11,67\% versus 6,24\% de MS). Além disso, houve maiores consumos de concentrado peletizado, consequentemente, o consumo de nutrientes da dieta, como proteína bruta, teve o mesmo comportamento, com valores de 70,3; 64,5; 52,3 e 51,65 g/dia para os animais das dietas com 0, 15, 30 e $45 \%$ de soro de queijo, respectivamente.

Por outro lado, a conversão e a eficiência alimentar não diferiram $(\mathrm{P}>0,05)$ entre as dietas (Tabela 3). A conversão alimentar variou de 2,38 nos animais que receberam leite de cabra integral, a 2,65 naqueles que receberam $30 \%$ de soro de queijo, enquanto a eficiência variou de 38,78 (dieta com $30 \%$ soro) a $43,22 \%$ para a dieta à base de leite de cabra integral.
O consumo total reflete a quantidade de matéria seca requerida para os animais obterem um peso específico em determinado tempo. Como o consumo é de 1,0 L/animal/dia da dieta líquida com leite de cabra integral ou com as diferentes proporções de soro de queijo bovino, as diferenças entre as dietas podem ser explicadas, em parte, pela qualidade das dietas utilizadas. Obviamente, as dietas com maiores proporções de leite de cabra forneceram mais nutrientes aos cabritos.

Os pesos do nascer até aos 14 dias de idade foram semelhantes $(\mathrm{P}>0,05)$ entre os sexos dos cabritos e variam de 3,16 a 4,41 e 2,89 a 3,92 kg para machos e fêmeas, respectivamente (Tabela 4$)$. Também não houve interação $(\mathrm{P}>0,05)$ entre a dieta e o sexo no desempenho ponderal dos cabritos até aos 70 dias de idade.

O efeito do sexo $(\mathrm{P}<0,05)$ tornou-se evidente a partir dos 21 dias de idade (Tabela 4). Os machos mantiveram pesos corporais superiores aos das fêmeas, com variação de 5,48 a $12,4 \mathrm{~kg}$, enquanto as fêmeas apresentaram pesos que variaram de 4,38 a 10,6 kg. Essa superioridade de peso dos machos deve-se à influência dos hormônios androgênicos sobre o desenvolvimento muscular (Lawrie, 2005).

Tabela 4 - Desempenho ponderal de cabritos alimentados com soro de queijo bovino em substituição ao leite de cabra na dieta

\begin{tabular}{|c|c|c|c|c|}
\hline & \multicolumn{2}{|c|}{ Sexo } & \multicolumn{2}{|c|}{ ANOVA } \\
\hline & Macho & Fêmea & Sexo & Dieta*Sexo \\
\hline \multicolumn{5}{|l|}{ Peso (kg de PV) } \\
\hline Ao nascer & $3,16 \pm 0,32$ & $2,89 \pm 0,46$ & ns & ns \\
\hline Aos 7 dias & $3,70 \pm 0,46$ & $3,07 \pm 0,55$ & $\mathrm{~ns}$ & ns \\
\hline Aos 14 dias & $4,41 \pm 0,30$ & $3,92 \pm 0,49$ & ns & ns \\
\hline Aos 21 dias & $5,48 \pm 0,37 a$ & $4,38 \pm 0,41 b$ & $*$ & ns \\
\hline Aos 28 dias & $6,12 \pm 0,92 a$ & $5,14 \pm 0,62 b$ & * & ns \\
\hline Aos 35 dias & $7,14 \pm 0,95 a$ & $5,76 \pm 0,55 b$ & * & ns \\
\hline Aos 42 dias & $8,53 \pm 0,96 a$ & $6,50 \pm 0,58 b$ & * & ns \\
\hline Aos 49 dias & $9,32 \pm 1,12 \mathrm{a}$ & $7,42 \pm 0,84 \mathrm{~b}$ & * & ns \\
\hline Aos 56 dias & $10,16 \pm 0,88 a$ & $8,53 \pm 0,57 b$ & * & ns \\
\hline Aos 63 dias & $11,42 \pm 1,41 \mathrm{a}$ & $9,44 \pm 1,41 b$ & * & ns \\
\hline Aos 70 dias & $12,40 \pm 1,70 a$ & $10,06 \pm 1,20 b$ & * & ns \\
\hline \multicolumn{5}{|l|}{ Ganho de peso diário (g/dia) } \\
\hline Do nascimento aos 70 dias & $132,0 \pm 23,71 \mathrm{a}$ & $102,4 \pm 15,0 b$ & * & ns \\
\hline Dos 28 aos 70 dias & $150,0 \pm 39,23 a$ & $117,1 \pm 20,0 \mathrm{~b}$ & * & ns \\
\hline
\end{tabular}

Médias com letras diferentes nas linhas são significativas $(\mathrm{P}<0,05)$ pelo teste Duncan. 
No entanto, os valores dos pesos corporais e ganhos de peso obtidos em ambos os sexos podem ser considerados satisfatórios, independentemente do plano nutricional a que foram submetidos. Aos 42 e 49 dias de idade, os machos e as fêmeas já tinham alcançado índice de aproximadamente 2,5 vezes o valor do peso ao nascer, o qual é um valor referencial para iniciar o processo de desaleitamento precoce dos cabritos em rebanhos leiteiros.

Houve efeito do sexo $(\mathrm{P}<0,05)$ sobre os ganhos de peso do nascimento aos 70 dias e dos 28 aos 70 dias de idade, com médias de 132,0; 102,4; 150,0 e 117,1 g/dia para machos e fêmeas, respectivamente, mas não ocorreu interação $(\mathrm{P}>0,05)$ entre a dieta vesus sexo para o ganho de peso dos cabritos. Isso reflete a capacidade de desenvolvimento mais precoce dos machos em relação às fêmeas. No entanto, num sistema de produção de cabras leiteiras, a criação dos machos pode onerar os custos, principalmente se não forem alimentados com um sucedâneo de baixo valor comercial ou, ainda, se não forem animais puros-de-origem para posterior comercialização como reprodutores a preços que compensem essa prática, o que não ocorre com as fêmeas, já que serão as futuras matrizes de reposição do rebanho.

Verificou-se efeito $(\mathrm{P}<0,05)$ do nível de soro de queijo bovino sobre a receita bruta média, custos com alimentação, margem bruta média e rentabilidade média (Tabela 5).

A renda bruta média variou de $\mathrm{R} \$ 35,95$ a $\mathrm{R} \$ 45,50$ e as dietas com até $15 \%$ de substituição do leite por soro de queijo apresentaram as maiores receitas brutas (R\$ $45,50$ e $\mathrm{R} \$ 38,85)$, uma vez que os animais apresentavam os maiores pesos corporais aos 70 dias de idade. No entanto, os custos relativos ao consumo de alimentos foram mais altos e representaram 52,30 e 51,97\% na alimentação dos cabritos que receberam leite de cabra integral e dos alimentados com 15\% de soro de queijo, respectivamente, refletindo de forma direta na margem bruta e na rentabilidade média.

O custo de alimentação no nível de $30 \%$ de substituição do leite de cabra pelo soro de queijo bovino foi intermediário (47,37\%). A rentabilidade média foi similar à obtida com $15 \%$ de soro de queijo, em torno de $110,82 \%$. No nível de $45 \%$ de soro de queijo, o custo de alimentação alcançou em torno de 37,22\%, a margem bruta média foi de $\mathrm{R} \$ 22,57$, semelhante ao das demais dietas, mas promoveu a melhor rentabilidade financeira, com média de 168,0\%, comprovando que o soro de queijo pode ser uma alternativa para reduzir os custos com alimentação dessa categoria animal.

Montenegro et al. (1998) recomendaram a substituição do leite de vaca por até $60 \%$ de soro de queijo no aleitamento de cabritos dos 35 aos 84 dias de idade como forma de aumentar a receita líquida dos produtores.

Como citado anteriormente, na dieta com $45 \%$ de soro de queijo, os consumos de leite de cabra integral e de soro foram de 269,0 e 220,5 litros. Além do favorecimento em termos financeiros, há o benefício ambiental, uma vez que o soro de queijo não é totalmente utilizado pela indústria de laticínios, e o excesso torna-se um resíduo poluente. Quando utilizado na alimentação animal, pode ser transformado em proteína de excelente qualidade e aumenta, indiretamente, a renda da caprinocultura leiteira.

No entanto, apesar de ser um subproduto de baixo custo, o uso do soro de queijo como sucedâneo para cabritos envolve os custos de transporte do laticínio à unidade produtiva rural, de conservação e de armazenamento.

Tabela 5 - Análise econômica, em relação ao peso vivo, de cabritos alimentados com soro de queijo bovino em substituição ao leite de cabra, considerando custo zero para obtenção dos cabritos ${ }^{1}$

\begin{tabular}{|c|c|c|c|c|}
\hline \multirow{2}{*}{$\begin{array}{l}\text { Nível de soro de queijo } \\
\text { bovino (\%) }\end{array}$} & \multicolumn{4}{|c|}{ Variável } \\
\hline & $\begin{array}{l}\text { Receita bruta } \\
\text { média ( } \mathrm{R} \$ \text { /cabrito) }\end{array}$ & $\begin{array}{c}\text { Custos com } \\
\text { alimentação }{ }^{2} \text { (R\$/cabrito) }\end{array}$ & $\begin{array}{c}\text { Margem bruta } \\
\text { média ( } \mathrm{R} \$ \text { /cabrito) }\end{array}$ & $\begin{array}{l}\text { Rentabilidade } \\
\text { média (\%) }\end{array}$ \\
\hline 0 & $45,50 a$ & $23,80 a$ & $21,69 a$ & $90,73 b$ \\
\hline 15 & $38,85 b$ & $20,19 b$ & $18,65 a$ & $92,02 b$ \\
\hline 30 & $34,60 b$ & $16,39 c$ & $18,20 a$ & $110,82 b$ \\
\hline 45 & $35,95 b$ & $13,38 d$ & $22,57 \mathrm{a}$ & $168,15 a$ \\
\hline
\end{tabular}

Médias com letras diferentes nas colunas são significativas $(\mathrm{P}<0,05)$ pelo teste Duncan.

${ }^{1}$ Cotação média do dólar comercial em outubro de 2007 foi de R\$ 1,80 .

2 Alimentos utilizados para o cálculo foram leite/soro, feno e concentrado.

\section{Conclusões}

A substituição de até $45 \%$ do leite de cabra por de soro de queijo para aleitamento de cabritos é tecnicamente viável, disponibiliza mais leite para comercialização e proporciona melhor retorno econômico. Não é economicamente viável o uso de leite de cabra integral para criação de cabritos em rebanhos leiteiros. 


\section{Referências}

BESERRA, F.J.; BEZERRA, L.C.N.M.; SILVA, E.M.C. et al. Efeito do aleitamento artificial à base de soro de queijo de leite cabra sobre as características da carcaça e da carne de cabritos "mamão" do tipo genético three cross. Ciência Rural, v.33, n.5, p.929-935, 2003.

GALINA, M.A.; PALMA, J.M.; PACHECO, D. et al. Effect of goat milk, cow milk, cow milk replacer and partial substitution of the replacer mixture with whey on artificial feeding of female kids. Small Ruminant Research, v.17, n.2, p.153-158, 1995.

GENANDOY, H.; SAHLU, T.; DAVIS, J. et al. Effects of different feeding methods on growth and harvest traits of young Alpine kids. Small Ruminant Research, v.44, n.1, p.81-87, 2002.

INSTITUTO BRASILEIRO DE GEOGRAFIA E ESTATÍSTICA IBGE. Pesquisa Pecuária Municipal. Disponível em: <http:// www.ibge.gov.br/home/estatistica/indicadores/agropecuaria/ producaoagropecuaria/default.shtm $>$ Acesso em: 10/4/2008.

LANA, G.R.Q.; ROSTAGNO, H.S.; DONZETE, J.L. et al. Efeito de programas de restrição alimentar sobre o desempenho produtivo e econômico e a deposição de gordura na carcaça de frango de corte. Revista Brasileira de Zootecnia, v.28, n.6, p.1302-1309, 1999.

LAWRIE, R.A. Ciência da carne. Trad. Jane Maria Rubensam. 6.ed. Porto Alegre: Artmed, 2005. 384p.

LYFORD JR., S.J. Crecimento y desarrollo del aparato digestivo de los rumiantes. In: CHURCH, D.C. (Ed.). EL rumiante: fisiología digestiva y nutrición. Zaragoza: Acribia, 1993, p.47-68.

MACHADO, R.M.G.; SILVA, P.C.; FREIRE, V.H. Controle ambiental em indústrias de laticínios. Brasil Alimentos, v.7, p.34-36, 2001.
MARTINS, T.D.D.; PIMENTA FILHO, E.C.; COSTA, R.G. et al. Soro de queijo líquido na alimentação de suínos em crescimento. Revista Ciências Agronômicas, v.39, n.2, p.301-307, 2008.

MINISTÉRIO DA FAZENDA [2007]. Dólar Fiscal da Receita Federal. Disponível em:<http://www.portalbrasil.net/2007/ indices/dolar_riscopais_outubro.htm> Acesso em: 2/10/2008.

MONTENEGRO, M.P.; AZEVEDO, A.R.; BARROS, N.N. et al. Uso do soro de queijo de cabra no aleitamento artificial de cabritos. Revista Brasileira de Zootecnia, v.27, n.6, p.1212-1217, 1998.

NUNES, I.J. Cálculo e avaliação de rações e suplementos. Belo Horizonte: FEP-MVZ Editora, 1998. 185p.

OLIVEIRA, J.B.; PIRES, A.J.V.; CARVALHO, G.G.P. et al. Subprodutos industriais na ensilagem de capim-elefante para cabras leiteiras: consumo, digestibilidade de nutrientes e produção de leite. Revista Brasileira de Zootecnia, v.39, n.2, p.411-418, 2010.

RIBEIRO, M.N.; PIMENTA FILHO, E.C.; ALMEIDA, C.C. et al. Características físico-químicas da carne de caprinos submetidos a diferentes níveis de substituição do leite por soro de queijo durante o aleitamento. Revista Brasileira de Zootecnia, v.26, n.3, p.595-598, 1997.

STATISTICAL ANALYSIS SYSTEM - SAS. SAS-STAT. User's guide. Carry: SAS Institute, 1997. 1167p.

VALADARES FILHO, S.C.; MAGALHÃES, K.A.; ROCHA JR., V.R.R. et al. Tabelas brasileiras de composição de alimentos para bovinos. 2.ed. Viçosa, MG: UFV; DZO; DPI, 2006. 329p.

VAN SOEST, P.J. Nutritional ecology of the ruminant. 2.ed. Ithaca: Cornell University Press, 1994. 476p. 